\title{
Rumores después del sismo de septiembre de 2017 en México
}

\author{
Bruno Lutz ${ }^{1}$
}

Fecha de recepción: 8 de octubre de 2018

Fecha de aprobación: 6 de mayo de 2019

Fecha de publicación: 30 de julio de 2019

\begin{abstract}
Resumen
En este artículo se analiza la difusión de informaciones verosímiles y desmentidos en los días siguientes al terremoto del 19 de septiembre de 2017 en México. A la multiplicación de los rumores en las redes sociales respondieron los desmentidos oficiales. En este periodo de emergencia, se dio una guerra informativa entre las autoridades y los medios masivos de comunicación, por un lado, y los ciudadanos en red por el otro. Pero la campaña antirumores llevada a cabo por el gobierno fue severamente cuestionada cuando la Armada de México confesó haber participado en la difusión del rumor de la niña Frida Sofía, supuestamente atrapada viva debajo de los escombros de su escuela. Asimismo, en este estudio se investiga las implicaciones de la propagación de rumores en situación de desastre natural, en el marco de una batalla por el monopolio de la producción de la verdad.
\end{abstract}

Palabras clave: desmentido, México, noticia falsa, rumor, terremoto

\section{Rumors after the earthquake of September 2017 in Mexico}

\begin{abstract}
This article analyzes the dissemination of credible information and denials in the days following the earthquake of September 19, 2017. The multiplication of rumors in social networks was responded with official denials. During this period of emergency, there was an informative war between the authorities and mass media on the one hand and "net citizens" on the other. But the antirumor campaign carried out by the government was severely questioned when the Mexican Navy confessed to having participated in spreading the rumor about the girl named Frida Sofia supposedly trapped alive under the rubble of her school. This study also examines the implications of rumors spread during contexts of natural disaster, within the framework of a battle for the monopoly over the production of truth.
\end{abstract}

Keywords: denial, earthquake, fake news, Mexico, rumor

1 Posdoctorado en Sociología, Universidad Nacional Autónoma de México. Profesor investigador del Departamento de Relaciones Sociales, Universidad Autónoma Metropolitana, Xochimilco, México. Contacto: brunolutz01@yahoo.com.mx 


\title{
Boatos após o sismo de setembro de 2017 no México
}

\begin{abstract}
Resumo
Neste artigo analisa-se a difusão de informações verossímeis e desmentidos nos dias seguintes ao terremoto do dia 19 de setembro de 2017 no México. À multiplicação dos boatos nas redes sociais responderam os desmentidos oficiais. Neste período de emergência, houve uma guerra informativa entre as autoridades e os meios de comunicação, por uma parte, e os cidadãos em rede, por outra. Mas a campanha antiboatos impulsada pelo governo foi severamente questionada quando a Armada do México confessou ter participado na difusão do boato da menina Frida Sofía, quem supostamente permanecia com vida presa debaixo dos escombros de sua escola. Ao mesmo tempo, neste estudo realiza-se uma pesquisa sobre as implicações da propagação de boatos em situação de desastre natural, no marco de uma batalha pelo monopólio da produção da verdade.
\end{abstract}

Palavras-chave: desmentido, México, notícia falsa, boato, terremoto

\section{Introducción}

Los rumores existen desde tiempos inmemoriales, sin que los procesos de civilización hayan podido erradicarlos ${ }^{2}$. Los rumores forman parte de la vida de los pueblos. La circulación de noticias falsas es un hecho cotidiano: son relatos generalmente acéfalos que se caracterizan por ser incompletos, dinámicos y camaleónicos. Estas informaciones preocupantes (trágicas, la mayoría de las veces) ${ }^{3}$ se transmiten a través de redes de personas de confianza, y su contenido menciona a una figura de autoridad como fuente de información. Un rumor dice algo pertinente en un momento oportuno: se trata de un "régimen de verosimilitud", según Zires (2017, p. 724), que se inscribe en una coyuntura específica. "El rumor emplea tanto la deducción como la inducción. Especula sobre hechos no verificados, reivindicando su verosimilitud y su plausibilidad" (traducción propia, Paillard, 2009, p. 131).

Por ejemplo, en el Antiguo Testamento los rumores eran llamados "ruidos" y "murmullos". El empleo de estos vocablos remite a enunciados marginales que carecen de autor, pero cuyos auditores y propagadores se multiplican impunemente.

3 Nueve de cada diez rumores concierne una tragedia (Renard, 2006). 
Ahora bien, conviene señalar el rol de la verdad dentro del campo de la comunicación y un tema fundamental al respecto ha sido el de la propaganda. La propaganda ha dejado de ser una estrategia informativa de las fuerzas armadas durante conflictos bélicos para abarcar un amplio abanico de temas y asuntos (Young, 2001; Chomsky, 2002). Aunque este término está hoy en desuso, en provecho de términos como "orientación de la información", "manipulación mediática" y "políticas de posverdad", la construcción intencional de noticias falsas (fake news en inglés) es una práctica que se remonta muy lejos en el tiempo. Esta última tiene por objetivos inducir un sentimiento positivo hacia un actor determinado, legitimar decisiones políticas controvertidas, desprestigiar personalidades, empresas y/o regímenes políticos, provocar una aversión masiva hacia un blanco dado y siempre alimentar un sentimiento colectivo independientemente de los hechos. Asimismo, estas políticas de posverdad — vinculadas también con el grado de libertad de expresión de los ciudadanos y el empleo de la censura- son instrumentadas por dependencias gubernamentales. El rumor es entonces el producto estratégico de una noticia falsa.

Pero el rumor puede interpretarse también como una forma de comunicación cuyos interlocutores desconocen la fuente y no se dieron a la tarea de autentificarla por la premura de la noticia, la pertinencia de la información en un contexto específico, la falta de libertad de expresión y/o la confianza en quien transmitió dicha noticia. En situación de crisis, los rumores se multiplican para suplir una carencia de información, pero también para reducir el peso de las incertidumbres de hombres y mujeres sometidos al dictado de graves contingencias. Así, nos distanciamos de la aseveración de algunos estudiosos de considerar al rumor como una psicopatología que tiene como fuente la angustia (Allport y Postman, 1987; Reumaux, 1990, 2009), para considerar al rumor como una forma autónoma de saber social de libre expresión de opiniones (Miaille, 1999). 
En caso de guerra, violencia social, inestabilidad política y catástrofes naturales aparecen con más fuerza informaciones no verificadas que circulan a la par, y muchas veces en contraposición, con las noticias oficiales. En las situaciones antes mencionadas, el contexto peligroso que viven los sujetos pone virtualmente en riesgo su integridad, por lo que la población tiende a lanzarse en una búsqueda afanosa de noticias actualizadas y, eventualmente, de anuncios predictivos. La incertidumbre y el temor motivan en gran parte esta avidez de información. Un rumor tiene la particularidad de interesar a un número importante de individuos localizados en un espacio geográfico dado, por lo que constituye un fenómeno social por completo. De ahí la importancia de estudiar los rumores no solo como actos locutorios marginales (lapsus comunicativos), sino más ampliamente como fenómenos transitorios pero contundentes, capaces de convocar creencias y representaciones colectivas.

Desde su aparición, la sociología del rumor, como subdisciplina de la sociología general, se ha desplegado en diferentes direcciones según el peso relativo que el investigador ha otorgado a un aspecto o el otro de este complejo fenómeno (Aldrin, 2003; DiFonzo y Bordia 2007; Froissart, 2000). Debido al tema tratado en el presente artículo, nos interesaremos en resaltar, en las investigaciones publicadas sobre el rumor, la divulgación de información verosímil en un contexto de crisis. Los rumorólogos concuerdan en que la convergencia de miedos y riesgos tienden a fomentar la producción y circulación de rumores (Rouquette, 1990, 2009a, 2009b). Dentro de estos miedos se destacan aquellos relacionados con catástrofes naturales siempre imprevisibles: terremotos, inundaciones, huracanes y sequías (Bauman, 2007, p. 12). En estos casos, las informaciones verosímiles suelen buscar explicar lo ocurrido, encontrar un chivo expiatorio y/o estigmatizar a las autoridades por su negligencia. Al respecto, conviene mencionar el documentado estudio de Brodu (1990) sobre los rumores de sequía en la campiña francesa provocados por el temor de la modernización de las prácticas agrícolas, y el trabajo de Oh 
et al. (2010) sobre los rumores divulgados en Twitter después de un devastador terremoto en Haití. De manera general, en situaciones poscatastróficas se activan procesos sociales de reconstrucción de los acontecimientos que ponen en duda la versión oficial (Clavandier, 2007). Los rumores sobreinterpretan lo real: se presentan como una versión de los hechos, entreverando pruebas y conjeturas, indicios y sospechas.

El presente estudio surge de la preocupación por comprender los rumores en México durante los días que siguieron el sismo del 19 de septiembre del 2017 (19s). Esta situación, de una excepcional gravedad, desencadenó una serie de informaciones no verificadas que suplían un vacío informativo, en algunos casos, y en otros complementaban noticias oficiales. A los canales tradicionales de información (radio, televisión y medios impresos), se sumaron con fuerza las redes sociales, cuyos usuarios compartieron libremente noticias de primera y segunda mano, opiniones personales y rumores también. Involucrado personalmente como voluntario en diferentes sitios de derrumbes, no tuve ni el tiempo ni la voluntad de estudiar in situ los rumores que circulaban, ni mucho menos realizar encuestas sobre el tema ${ }^{4}$. Fue después del sonado desmentido del rumor de la niña Frida Sofía que me surgió la idea de investigar el fenómeno del rumor en los días que duró la emergencia. Entonces llevé a cabo una revisión biblio y hemerográfica muy amplia de las fuentes académicas sobre el tema, y consulté también las bases de datos de Redalyc, Jstor, Scielo y Persée. Además, el material periodístico era muy abundante, ya que se revisaron nueve periódicos publicados en la Ciudad de

4 Diferente fue el caso de Edgar Morin y sus colaboradores, quienes fueron contratados para acallar un poderoso rumor de secuestro de jovencitas en la ciudad francesa de Orléans (Morin, 1982). Se trató de una intervención sociológica ejemplar, llevada a cabo por un equipo de investigadores dotado de recursos técnicos y financieros. Diferente también es el estudio realizado por Fernández Poncella (2014) en el zócalo de la Ciudad de México, acerca del rumor del virus H1N1 después de su desaparición; encuesta acotada en sus alcances debido al hecho de que los entrevistados, o bien decían no acordarse del rumor o bien negaban haber creído en él y haberlo propagado. 
México, por lo que logré recolectar una cantidad significativa de información escrita tratando del fenómeno ${ }^{5}$. También visualicé alrededor de cincuenta videos publicados en Youtube abordando directa o indirectamente el tema de los rumores después del 19s, y seguí la información posteada en Facebook en los días siguientes al sismo. De tal forma que mi comprensión del fenómeno de los rumores iba a ser desde una perspectiva inductiva. Al analizar el conjunto de este material, descubrí que había una serie de antirumores difundidos por unidades administrativas federales (incluso desde antes del sismo) para combatir al rumor como forma genérica de comunicación; por otro lado, había rumores específicos con sus diferentes versiones, y finalmente había desmentidos por parte del gobierno de la República y organismos citados en dichos rumores. Es a partir de este descubrimiento que se ha organizado la exposición de nuestros argumentos.

La primera parte del artículo aborda la producción de antirumores como estrategia gubernamental, apoyada por actores colectivos del sector empresarial y de la sociedad civil, para modificar los "malos hábitos comunicativos" de la ciudadanía. El segundo apartado examina rumores específicos y los desmentidos oficiales correspondientes, desvelando una lógica de confrontación discursiva. En el tercer y último capítulo se detalla el rumor de Frida Sofía, rumor de gran alcance propagado por una institución gubernamental junto con una televisora, que puso en jaque la narrativa oficial antirumores llevada a cabo hasta ese entonces. Finalmente, en las conclusiones se retomarán los principales resultados obtenidos en el examen de los rumores en el periodo que siguió el sismo de septiembre de 2017, con el fin de, modestamente, contribuir a la constitución de ese campo de estudio en América Latina.

\footnotetext{
Se revisaron sistemáticamente los siguientes periódicos publicados del 19 al 30 de septiembre del 2017: El Universal, Reforma, La Jornada, Excelsior, Milenio, El Sol de México, El Financiero, El Economista y Publimetro.
} 


\section{Antirumores}

El martes 19 de septiembre, a las 13:14, dos horas apenas después del simulacro, se registró un sismo de 7.1 de magnitud en la escala de Richter, cuyo epicentro se encontraba a menos de 120 $\mathrm{km}$ de la Ciudad de México. Mucho más intenso y devastador que el sismo de 8.4 ocurrido en Chiapas el 7 de septiembre del mismo, el terremoto del 19s fue provocado por una violenta interacción intrapalaca, cuya aceleración máxima fue de 58.83 centímetros sobre segundo al cuadrado $\left(\mathrm{cm} / \mathrm{s}^{*} \mathrm{~s}\right)$, mientras que en el histórico sismo de 1985 había sido de $32.58 \mathrm{~cm} / \mathrm{s}^{*}$. Ese movimiento telúrico provocó cuantiosas perdidas humanas y daños materiales: los estados de Puebla, Morelos, Veracruz y Oaxaca fueron afectados, pero fue en la capital del país donde se registraron los mayores estragos. En total, 369 personas fallecieron, 337 fueron hospitalizadas, hubo decenas de miles de damnificados y se contabilizaron 16.630 edificios dañados en diversos grados (Roa, 2017).

En su primer mensaje después del sismo, el presidente de la República, de regreso de Oaxaca en helicóptero, dijo que no se veían afectaciones en la Ciudad de México. Con idéntica serenidad, el coordinador nacional de Protección Civil de la Secretaría de Gobernación, escribió en su cuenta de Twitter: "Al momento no se reportan daños. Se encuentran activos los protocolos de atención y respuesta". Pero en la noche de ese día el tono del primer mandatario cambió: "Les pido que estén atentos a la información oficial y las recomendaciones que difundimos por medio de las redes sociales y los medios de comunicación. (...) Permanezcan informados, no propaguen rumores y atiendan las recomendaciones de las autoridades" (Presidencia de la República, 2017a).

Junto con la presidencia de la República, la Secretaría de Gobernación (Segob) y el Centro Nacional de Prevención de Desastres (Cenapred) fueron las unidades administrativas que más antirumores difundieron. Los responsables de esos organismos transmitieron también a título personal esas advertencias. El secretario 
de Gobernación refirió en su cuenta de Twitter que, si bien puede haber réplicas, los sismos no se pueden predecir. "Por favor NO generen y $\mathrm{NO}$ crean en rumores. Estén atentos a información de cuentas oficiales y de las autoridades ${ }^{\prime \prime}{ }^{6}$, Medios masivos de comunicación nacionales y regionales repitieron y difundieron la solicitud del secretario de Gobernación. Horas después del temblor, la redacción del periódico Excelsior, en su versión electrónica, repitió el mensaje oficial e incluyó una cápsula informativa de la Secretaría de Gobernación (Segob) titulada: "Evita difundir rumores"7. Dos días después del sismo la misma dependencia publicó una serie de recomendaciones, dentro de las cuales se puede leer: "Evitar propagar rumores en redes sociales y en la comunidad. No difundir información si no es real. Mantenerse informado solo a través de cuentas oficiales: @PcSegob, @SEGOB_mx y @LUISFELIPE_P”. Por su lado, el Cenapred reiteraba en sus comunicados esta medida preventiva. "Evita propagar rumores en redes sociales y en la comunidad. No difundir información si no es real" (Boletín 317/17, del 20 de septiembre de 2017).

En este coro de advertencias oficiales para no crear ni difundir rumores, debe hacerse mención del volante difundido por la Procuraduría General de la República (2017) el 21 de septiembre, titulado: “Cómo ayudar a las personas afectadas por el \#sismo?", el cual explica los diferentes pasos para "curar" una información. En dicho documento se precisa que curar una información es "Verificar el origen, pertinencia y oportunidad de la información que te llega o que compartes", y enseguida se reitera el mensaje de no

\footnotetext{
Recuperado de https://twitter.com/osoriochong?lang=en

7 En esta cápsula de 43 ", la Segob señala: "Hacer un buen uso de las herramientas de comunicación virtual es clave para prevenir y enfrentar la violencia y la delincuencia", antes de presentar recomendaciones detalladas sobre cómo distinguir una información real de un rumor: "3.- Fíjate si la fecha del evento, el lugar o los nombres coinciden con lo que se quiere comunicar, 4.- Corrobora la información y consulta fuentes fijas en las que confíes, 5.- Si puedes acudir a una fuente oficial ¡hazlo!". Recuperado de http://www.excelsior.com.mx/ nacional/2017/09/19/1189466
} 
difundir rumores y de transmitir una información (relativa al sismo) a las autoridades solo después de haberla verificado.

Por su parte, la Secretaría de Salud, tres días después del sismo, aconsejaba: "Evita rumores y mantente informado solo con fuentes oficiales", y en comunicado posterior modificó su mensaje al dirigirse al lector en la tercera persona del singular conminándolo a actuar solo en caso de urgencia: "Evite los rumores y solo llame al 911 si tiene una emergencia" 8 . En cuanto al Fideicomiso \#FuerzaMéxico, creado por empresarios nacionales, compartió una Guía titulada "¿Cómo ayudar a compartir información?". En esta tarjeta se dice: "Antes de difundir información, noticias o alertas en relación a los efectos del sismo: 1./ Verifica que la fuente es confiable; 2./ Rectifica la información con las autoridades correspondientes antes de tomar alguna acción; 3./ $\mathrm{Si}$ las autoridades no han informado comunícate con éstas. Recuerda que alarmar con rumores o noticias falsas entorpece los operativos de ayuda" (El Heraldo de México, 2017).

Dentro de lo que un ciudadano debía hacer después de un movimiento telúrico, aparecía invariablemente una nota referida al no propagar información no verificada y remitirse siempre a las plataformas informativas del gobierno. Para contrarrestar el rumor cíclico de un sismo de gran magnitud, el Cenapred había difundido varios mensajes en los meses anteriores al terremoto del 19 de septiembre 2017, uno de los cuales advertía: "Atiende sólo la información que provenga de fuentes oficiales, y que está basada en evidencias científicas" (Cenapred, 2017). La ausencia de referencia a un rumor preciso permitió a las autoridades mantener ese mismo discurso, independientemente de la aparición de nuevos rumores. Asimismo, se presentaba tanto como una advertencia para impedir la participación de los ciudadanos en la difusión de rumores, como una llamada de atención de corte paternalista hacia quienes contribuyeron en la amplificación de

Comunicados del 22 de septiembre de 2017 y del 25 de septiembre de 2017. 
las murmuraciones. Mediante este mensaje, el gobierno buscaba recordar su rol como garante del orden social y moral, descalificando cualquier otra opinión que no fuera de fuente oficial, ya que la ciencia - la única en tener la verdad y, por ende, la única fuente certificada- estaba del lado del gobierno.

En México el sistema de información política parece regirse por el principio de que el secreto es un instrumento básico de poder, de tal manera que la explicación de los fenómenos y las decisiones políticas se dejan en gran medida a la libre interpretación de la opinión pública que además cuenta con pocos elementos fundamentados de juicio. De hecho, la anécdota, el chisme y el rumor son fuente importante de la información política de que dispone el mexicano. Esto ha significado que exista una predisposición muy clara a aceptar y transmitir el rumor, y en general, aun cuando una especie se califique de tal, la gente tienda a concederle el beneficio de la duda. (Loaeza, 1977, p. 575)

Escritas hace cuatro décadas, estas palabras relativas a la propagación del rumor en México han conservado su actualidad.

\section{Rumores y desmentidos}

En su lucha por acallar los murmullos y ruidos cibernéticos, las autoridades se vieron obligadas a publicar desmentidos de rumores específicos; la repetición del mensaje de buena conducta ciudadana no había sido suficiente. Concretamente, el titular de la Secretaría de Gobernación (Segob), así como la Unidad de Protección Civil del estado de Sonora y la Presidencia de la República, desmintieron la información que circulaba en la red social WhatsApp sobre "otro gran sismo" próximo a ocurrir en los estados de Sonora, Baja California y Chihuahua (Villamil, 2017). El secretario de Gobernación, en su cuenta de Twitter, pidió a la población no generar ni crear rumores acerca de un nuevo gran sismo, como se ha difundido en redes sociales. Este miedo transformado en rumor encuentra su origen en: 1) el conocimiento 
aproximado de la existencia de la "falla de San Andrés"; 2) el haber escuchado al respecto del movimiento de las placas tectónicas; 3) el saber que réplicas siguen invariablemente a un terremoto; y 4) contar con una larga experiencia de resentir sismos.

Otro caso de desmentido es del presidente de la República quien, en un comunicado fechado del 21 de septiembre, precisaba:

En la Ciudad de México hay 38 edificios siniestrados, donde todavía hoy en día se están realizando labores de rescate, y ha habido algunas filtraciones, o rumores falsos, de estos que llegan a correr a veces en las redes sociales, de que se habrá de suspender la labor de rescate. Las labores de rescate continúan en la Ciudad de México. No se suspenden. (Presidencia de la República, 2017b)

Esta vez el desmentido pretendía terminar con el rumor de que las labores de rescate de personas no iban a durar más de tres días (el protocolo internacional indica que la búsqueda de sobrevivientes debe tener una duración mínima de 72 horas), y que las autoridades empleaban maquinaria pesada cuando posiblemente había todavía personas con vida debajo de los escombros. Es posible aseverar que las diferentes versiones de este rumor tienen su origen en el hecho de que: 1) las Fuerzas Armadas tomaron el control de las labores de rescate, desplazando al personal de protección civil, los rescatistas profesionales y los voluntarios de la sociedad civil; 2) el hecho de ver maquinaria pesada trabajando en los sitios donde se derrumbaron inmuebles; 3) la aparente despreocupación de las autoridades por rescatar trabajadoras ilegales atrapadas debajo de sus talleres en un edificio del centro (Turati, 2017); y 4) la salida de rescatistas internacionales unos días apenas después de haber llegado, debido a una solicitud del gobierno mexicano.

Otro rumor fue la información que relacionaba, según las versiones, el temblor en la región de Chiapas del 7 de septiembre y/o el sismo del 19 del mismo en la Ciudad de México con pruebas nucleares norcoreanas. La diputada y actriz Carmen Salinas fue quien, muy probablemente, contribuyó a difundir esa informa- 
ción, declarando en una entrevista televisiva: "Creo que la tierra está enojada por este señor de Corea del Norte que aviente y aviente bombas" (Vanguardia, 2017). A pesar del poco peso que tuvo su opinión personal, varias fueron las informaciones que podían dar sustento a ese rumor: 1) sismógrafos en México registraron las ondas sísmicas provocadas por las pruebas atómicas en Corea del Norte; 2) el secretario de las Naciones Unidas había calificado de "profundamente desestabilizador" el último ensayo nuclear de la nación asiática; 3) la expulsión del embajador norcoreano de México; 4) el día siguiente 20 de septiembre, el régimen de Pyongyang iba a celebrar la fiesta nacional. No obstante la posibilidad de relacionar los elementos antes mencionados para dar cientificidad a ese rumor, pocos lo hicieron debido a las características de la persona antes mencionada, siendo su lenguaje coloquial y sus argumentos dispares, además de carecer de autoridad científica y moral para expresar una opinión certera sobre el fenómeno telúrico. Este rumor no fue desmentido por ninguna autoridad.

Otro rumor más difundido se refería a los trámites que las personas damnificadas debían realizar para acceder a recursos federales. Al respecto, la Segob emitió un comunicado tres días después del sismo en el que recordó que las personas no requerían hacer ningún trámite directo ante el Fondo de Desastres Naturales (Fonden), pues este Fondo no opera a través de personas particulares, sino mediante las dependencias de los gobiernos federales y estatales. "En este momento de emergencia es importante ignorar los rumores y consultar fuentes oficiales para verificar la información", recalcaba el mensaje (Secretaría de Gobernación, 2017b). De esta forma se planteaba que las plataformas informativas del gobierno constituían la única referencia confiable acerca del sismo y las labores de rescate y apoyo a damnificados. Este rumor puede explicarse por el hecho de que: 1) miles de familias tuvieron que abandonar su domicilio porque había sido destruido o severamente dañado por el terremoto; 2) la situación de los damnificados en los albergues era muy precaria; 3 ) el gobierno federal y el gobierno de la Ciudad de México repetían que brindarían todo el apoyo a las 
personas damnificadas, sin que éstas pudieran notar algo concreto; 4) en los sitios oficiales de internet no aparecía trámite alguno para obtener recursos del Fonden. Así, el rumor que decía que los damnificados debían de solicitar un apoyo económico al Fonden a través de intermediarios fue desmentido por las autoridades.

\section{Cuadro 1}

Lista de rumores después del sismo del 19 de septiembre de 2017

\begin{tabular}{|c|c|c|}
\hline Rumor & Características & Realidad \\
\hline $\begin{array}{l}\text { El IMSS necesita } \\
\text { con urgencia do- } \\
\text { nadores de san- } \\
\text { gre (19 de sep- } \\
\text { tiembre) }\end{array}$ & $\begin{array}{l}\text { Sentido de urgencia en un } \\
\text { momento de alta incertidum- } \\
\text { bre. Sugiere una situación hu- } \\
\text { manitaria grave. }\end{array}$ & $\begin{array}{l}\text { El IMSS aclara que sus bancos } \\
\text { de ayuda cuentan con suficien- } \\
\text { te sangre para atender a los } \\
\text { primeros heridos. No pide un } \\
\text { número de donadores, pues } \\
\text { desconoce la cifra de heridos y } \\
\text { fallecidos durante el sismo. }\end{array}$ \\
\hline $\begin{array}{l}\text { La ONU predi- } \\
\text { ce un sismo de } \\
10.5 \text { grados, mu- } \\
\text { chísimo mayor } \\
\text { al registrado el } \\
\text { martes (19 de } \\
\text { septiembre) }\end{array}$ & $\begin{array}{l}\text { Tras un sismo de gran mag- } \\
\text { nitud, por lo general ocurren } \\
\text { réplicas. Aprovecha la ansie- } \\
\text { dad social que está expectante } \\
\text { sobre el futuro inmediato. Ci- } \\
\text { ta a una fuente de renombre } \\
\text { internacional. }\end{array}$ & $\begin{array}{l}\text { Nada puede predecir un sismo } \\
\text { y menos con claridad de su } \\
\text { magnitud. La ONU envía un } \\
\text { comunicado desmintiendo la in- } \\
\text { formación. La escala de Richter } \\
\text { nunca ha reportado un temblor } \\
\text { de } 10 \text { grados. El máximo regis- } \\
\text { trado fue de } 9.5 \text { grados en 1960, } \\
\text { en Chile. La UNAM también } \\
\text { desmiente el rumor. }\end{array}$ \\
\hline $\begin{array}{l}\text { El volcán Po- } \\
\text { pocatépetl hi- } \\
\text { zo erupción por } \\
\text { el sismo (19 de } \\
\text { septiembre) }\end{array}$ & $\begin{array}{l}\text { La información proviene de } \\
\text { una fuente (Webcams de Mé- } \\
\text { xico) que mantiene cobertura } \\
\text { permanente del volcán. Los } \\
\text { responsables de las redes so- } \\
\text { ciales de Webcams de México } \\
\text { dan por hecho que la exhala- } \\
\text { ción está relacionada con el } \\
\text { sismo. }\end{array}$ & $\begin{array}{l}\text { Protección Civil inmediata- } \\
\text { mente aclaró que el Popocaté- } \\
\text { petl se mantiene en Amarilla } \\
\text { Fase } 2 \text {, como en otros días sin } \\
\text { sismo. }\end{array}$ \\
\hline $\begin{array}{l}\text { El edificio que } \\
\text { alberga el centro } \\
\text { de espectáculos } \\
\text { Plaza Condesa } \\
\text { está a punto de } \\
\text { colapsar (19 de } \\
\text { septiembre) }\end{array}$ & $\begin{array}{l}\text { El edificio se encuentra en una } \\
\text { de las zonas más afectadas } \\
\text { por los terremotos de } 2017 \text { y } \\
\text { de 1985. El edificio contiguo } \\
\text { manifiesta daños graves. Los } \\
\text { militares amplían el períme- } \\
\text { tro de resguardo bajo el edifi- } \\
\text { cio del Plaza Condesa. }\end{array}$ & $\begin{array}{l}\text { El Ejército y la Marina cercaron } \\
\text { un perímetro a } 30 \text { metros de } \\
\text { la construcción por posibles } \\
\text { riesgos ante las cuarteaduras } \\
\text { en sus pisos más elevados. El } \\
\text { propio jefe de gobierno de la } \\
\text { Ciudad de México sostuvo que } \\
\text { el inmueble no sufrió daños } \\
\text { estructurales y que no existe } \\
\text { riesgo de colapso. }\end{array}$ \\
\hline
\end{tabular}




\begin{tabular}{|c|c|c|}
\hline $\begin{array}{l}\text { Destruida una } \\
\text { rampa en el Pe- } \\
\text { riférico con di- } \\
\text { rección a ave- } \\
\text { nida Rómulo } \\
\text { O'Farrill (19 de } \\
\text { septiembre) }\end{array}$ & $\begin{array}{l}\text { Hay expectativas entre las } \\
\text { personas por conocer los } \\
\text { daños en la infraestructura } \\
\text { urbana de la ciudad tras el } \\
\text { sismo Se difunde una imagen } \\
\text { que muestra grietas similares } \\
\text { a las de edificios que sí se vie- } \\
\text { ron afectados por el sismo en } \\
\text { una rampa vehicular en uso. }\end{array}$ & $\begin{array}{l}\text { La Secretaría de Obras y Servi- } \\
\text { cios del Gobierno de la Ciudad } \\
\text { de México (Sobse) desmintió } \\
\text { la noticia y descartó cualquier } \\
\text { tipo de daño estructural. Aclara } \\
\text { que hubo un cierre temporal } \\
\text { por afectaciones del sismo en } \\
\text { edificios cercanos. }\end{array}$ \\
\hline $\begin{array}{l}\text { Se colapsó un } \\
\text { edificio ubicado } \\
\text { en América es- } \\
\text { quina con Divi- } \\
\text { sión del Norte } \\
\text { ( } 20 \text { de septiem- } \\
\text { bre) }\end{array}$ & $\begin{array}{l}\text { La ubicación del edificio es } \\
\text { cercana a otras zonas en las } \\
\text { que varios inmuebles sufrie- } \\
\text { ron afectaciones severas. La } \\
\text { noticia se dio un día después } \\
\text { del sismo, cuando aún no ha- } \\
\text { bía certeza sobre los edificios } \\
\text { que efectivamente estaban a } \\
\text { punto de colapsar. }\end{array}$ & $\begin{array}{l}\text { No hay ningún edificio colap- } \\
\text { sado en la ubicación dada en } \\
\text { redes sociales, por lo que la } \\
\text { información solo ocasionó in- } \\
\text { tenso tráfico vehicular. }\end{array}$ \\
\hline $\begin{array}{l}\text { Angélica Rivera, } \\
\text { esposa del pre- } \\
\text { sidente Enrique } \\
\text { Peña Nieto, en- } \\
\text { vía cajas vacías } \\
\text { de ayuda a dam- } \\
\text { nificados ( } 20 \text { de } \\
\text { septiembre) }\end{array}$ & $\begin{array}{l}\text { Desde antes del sismo, la } \\
\text { sociedad se encuentra en un } \\
\text { estado de crispación por los } \\
\text { escándalos de corrupción } \\
\text { que rodean la administra- } \\
\text { ción en curso. La aprobación } \\
\text { del presidente Enrique Peña } \\
\text { Nieto se encuentra en un bajo } \\
\text { nivel. }\end{array}$ & $\begin{array}{l}\text { Las imágenes corresponden al } \\
8 \text { y } 9 \text { de septiembre, días en los } \\
\text { que Angélica Rivera recababa } \\
\text { apoyo para los damnificados } \\
\text { del sismo del } 7 \text { de septiembre, } \\
\text { en Oaxaca y Chiapas. El día 21, } \\
\text { el gobierno federal abrió las } \\
\text { cajas y mostró el contenido. }\end{array}$ \\
\hline $\begin{array}{l}\text { \#AyudanDog. } \\
\text { La marca de ali- } \\
\text { mentos Purina } \\
\text { apoya a los pe- } \\
\text { rros de rescate } \\
\text { ( } 20 \text { de septiem- } \\
\text { bre) }\end{array}$ & $\begin{array}{l}\text { Varias empresas comenzaron } \\
\text { a ofrecer ayuda inmediata- } \\
\text { mente después del sismo } \\
\text { del } 19 \text { de septiembre. La } \\
\text { campaña difundida tiene los } \\
\text { elementos de una campaña } \\
\text { oficial de la empresa. Varios } \\
\text { perros rescatistas han tenido } \\
\text { una difusión mediática im- } \\
\text { portante. }\end{array}$ & $\begin{array}{l}\text { Purina aclaró que la campaña } \\
\text { fue válida para mascotas en } \\
\text { Colombia, y con motivo de } \\
\text { un desastre natural ocurrido } \\
\text { en julio allí. El día } 21 \text {, Purina } \\
\text { anuncia apoyo de } 50.000 \text { por- } \\
\text { ciones de comida a brigadistas } \\
\text { y perros de rescate por el sis- } \\
\text { mo en México. }\end{array}$ \\
\hline $\begin{array}{l}\text { Maquinaria pe- } \\
\text { sada removerá } \\
\text { escombros (20 } \\
\text { de septiembre) }\end{array}$ & $\begin{array}{l}\text { Hay distintas versiones sobre } \\
\text { un mismo evento de fuentes } \\
\text { ciudadanas. La información } \\
\text { apócrifa sobre la inexistente } \\
\text { Frida Sofía robusteció la des- } \\
\text { confianza con las autoridades. }\end{array}$ & $\begin{array}{l}\text { El gobierno federal y capitalino } \\
\text { desmienten la información, ya } \\
\text { que el protocolo internacional } \\
\text { de rescate que debe seguirse } \\
\text { después de un sismo establece } \\
\text { un tiempo de } 72 \text { horas como } \\
\text { mínimo para buscar sobrevi- } \\
\text { vientes y el terremoto ocurrió el } \\
\text { día } 19 .\end{array}$ \\
\hline
\end{tabular}




\begin{tabular}{|c|c|c|}
\hline $\begin{array}{l}\text { Muere primer } \\
\text { perro rescatista } \\
(20 \text { de } \\
\text { bre })\end{array}$ & $\begin{array}{l}\text { Los perros Frida y Titán han } \\
\text { rescatado muchas personas } \\
\text { que se encontraban en los } \\
\text { escombros de varios edificios } \\
\text { derrumbados. Varios perros } \\
\text { rescatistas han tenido una di- } \\
\text { fusión mediática importante. }\end{array}$ & $\begin{array}{l}\text { Ningún escuadrón de rescate } \\
\text { reporta el fallecimiento de un } \\
\text { perro con ese nombre y los } \\
\text { cuerpos de ayuda desconocen } \\
\text { si este ejemplar haya salvado } \\
13 \text { vidas durante su actividad. }\end{array}$ \\
\hline $\begin{array}{l}\text { El PRI se apro- } \\
\text { vecha del mo- } \\
\text { mento }(21 \text { de } \\
\text { septiembre })\end{array}$ & $\begin{array}{l}\text { Los escándalos de corrupción } \\
\text { que rodean a funcionarios } \\
\text { públicos que pertenecen al } \\
\text { PRI han afectado su imagen } \\
\text { pública. Varios partidos polí- } \\
\text { ticos, incluyendo al PRI, han } \\
\text { realizado campañas electora- } \\
\text { les con recursos públicos. }\end{array}$ & $\begin{array}{l}\text { Las fotografías son del } 2012 \text { y } \\
\text { corresponden a obsequios para } \\
\text { la población durante la campa- } \\
\text { ña presidencial en el Edomex y } \\
\text { Veracruz. }\end{array}$ \\
\hline $\begin{array}{l}\text { \#FridaSofia (22 } \\
\text { de septiembre) }\end{array}$ & $\begin{array}{l}\text { La cobertura de los medios } \\
\text { de comunicación (televisión, } \\
\text { radio, prensa impresa y di- } \\
\text { gital) se dedicó durante más } \\
\text { de } 15 \text { horas a transmitir el su- } \\
\text { puesto rescate. La expectativa } \\
\text { por encontrar a más personas } \\
\text { con vida obligó al público y } \\
\text { a los voluntarios rescatistas a } \\
\text { permanecer atentos a un caso } \\
\text { como el de la niña Frida Sofía. }\end{array}$ & $\begin{array}{l}\text { La Secretaría de Marina con- } \\
\text { firmó que la información fue } \\
\text { falsa, que nunca hubo una niña } \\
\text { con ese nombre bajo los escom- } \\
\text { bros. Información acerca de que } \\
\text { la niña fue vista, contactada y } \\
\text { alimentada con agua resultó ser } \\
\text { falaz. Televisa responsabilizó a } \\
\text { la Semar, dependencia que se } \\
\text { disculpó por la noche. }\end{array}$ \\
\hline $\begin{array}{l}\text { El Chapo dona } \\
\text { por el sismo ( } 22 \\
\text { de septiembre) }\end{array}$ & $\begin{array}{l}\text { Se han realizado múltiples } \\
\text { donaciones, tanto nacionales } \\
\text { como internacionales, para } \\
\text { ayudar a las labores de resca- } \\
\text { te y reconstrucción después } \\
\text { del sismo. Existen rumores } \\
\text { sobre el carácter de benefac- } \\
\text { tor de Joaquín Guzmán Loera } \\
\text { para con la población civil de } \\
\text { su lugar de origen. }\end{array}$ & $\begin{array}{l}\text { Ninguna fuente acreditada ha } \\
\text { desmentido o confirmado la } \\
\text { información. }\end{array}$ \\
\hline $\begin{array}{l}\text { Se solicita do- } \\
\text { cumentación a } \\
\text { dueños de in- } \\
\text { muebles afec- } \\
\text { tados para reci- } \\
\text { bir recursos del } \\
\text { Fonden (22 de } \\
\text { septiembre) }\end{array}$ & $\begin{array}{l}\text { Existe la necesidad de recursos } \\
\text { para continuar con las labores } \\
\text { de rescate, apuntalar inmue- } \\
\text { bles o para iniciar la remoción } \\
\text { de escombros. El Fondo de } \\
\text { Desastres Naturales (Fonden) } \\
\text { es usado para la atención y } \\
\text { recuperación de los efectos } \\
\text { que produzca un fenómeno } \\
\text { natural, como lo es el sismo } \\
\text { del pasado } 19 \text { de septiembre. }\end{array}$ & $\begin{array}{l}\text { La Secretaría de Gobernación } \\
\text { advirtió a la ciudadanía que no } \\
\text { es necesario que ningún parti- } \\
\text { cular presente documentación } \\
\text { alguna para recibir recursos del } \\
\text { Fonden, ya que este fondo se } \\
\text { maneja a través de las depen- } \\
\text { dencias gubernamentales. }\end{array}$ \\
\hline
\end{tabular}

Fuente: Lucas (2017). 
La difusión de desmentidos por parte de las autoridades federales, desde el primer día de emergencia, recuerda la estrategia del gobierno veracruzano, quien trató de callar el rumor de secuestros de niños en escuelas y balaceras en la ciudad portuaria en agosto de 2011, sospechando las autoridades estatales de tener vínculos con la mafia (Zires, 2017). En las redes sociales circulaba información, no siempre auténtica, sobre actividades delincuenciales y movilizaciones policíacas, por lo que los antirumores y la amenaza de persecución judicial de quienes propagaban rumores contribuyeron paradójicamente en reactivarlos. Tanto en Veracruz como en la Ciudad de México, los desmentidos oficiales no produjeron el efecto previsto, debido a la profunda resistencia del cuerpo social de creer en los políticos y los altos funcionarios del gobierno.

De manera general, la ciudadanía desconfía de las autoridades, como lo confirmó un censo reciente ${ }^{9}$, y en una situación de crisis vuelve a manifestarse de manera viral esa desconfianza. Además, los desmentidos surgieron cuando las autoridades no daban todavía un informe detallado sobre las pérdidas humanas y los daños materiales ocasionados por el sismo, por lo que ciertamente fue demasiado pronto para desmentir rumores.

Pues el momento de la denegación es una elección delicada. Denegar demasiado pronto, cuando el rumor no es más que un ruido localizado, correría el riesgo de provocar el efecto negativo antes señalado [alimentar nuevamente los rumores]. Denegar tarde, cuando el cuerpo social haya consolidado sus impresiones forjadas por el rumor que habrá tenido el monopolio de la palabra, corre el riesgo de ser ineficaz. (traducción propia, Kapferer, 1990, p. 115)

\footnotetext{
Los diputados, sindicatos y partidos políticos son las instituciones en la que menos confianza tienen los ciudadanos. Consulta Mitofsky. "México: confianza en instituciones 2016". Recuperado de http://www.consulta.mx/index.php/estudiose-investigaciones/mexico-opina/item/884-mexico-confianza-en-instituciones-2016
} 
Este fuerte llamado para recordar que las autoridades eran los únicos agentes facultados para informar con veracidad sobre lo ocurrido, llamado repetido por los medios masivos de comunicación, fue considerado sospechoso por una parte del público, porque se pensó que querían esconder cosas (la verdadera amplitud del desastre, el conocimiento de la siguiente réplica, la tardanza para actuar de los servicios de emergencia, la ineptitud de los políticos para coordinar las acciones de rescate, la corrupción para obtener permisos para la construcción de inmuebles, etc.). Este deseo repentino del gobierno por controlar la información relativa al terremoto tenía como efecto colateral reducir la libertad de expresión e información de los ciudadanos, ambas facultades garantizadas por la Constitución ${ }^{10}$. No obstante esta voluntad compartida del gobierno y de los medias para confinar a las personas en sus casas, con el pretexto de que ahí estarían informadas y no congestionarían las vialidades, la sociedad civil se organizó con gran velocidad para dar a conocer una información oportuna y certera sobre las labores de rescate.

Así, la mañana siguiente al temblor, unos ciudadanos crearon la plataforma digital \#Verificado19s, que se encargó de concentrar y averiguar la autenticidad de la información para ponerla a disposición de las autoridades y del público en general. Fue vista por millones de personas. Su éxito consistió precisamente en su metodología para recolectar información y confirmar su autenticidad. Se podía colaborar dando una información a partir de su presencia en el lugar de los hechos como testigo ocular, o bien proporcionando una información corroborada por al menos dos personas. Esta información recabada era a su vez cotejada inmediatamente por los equipos de voluntarios de \#Verificado19s, para luego mapear los daños y las necesidades en tiempo real

10 El artículo 6 de la Constitución mexicana afirma: “La manifestación de las ideas no será objeto de ninguna inquisición judicial o administrativa, sino en el caso de que ataque a la moral, los derechos de tercero, provoque algún delito o perturbe el orden público; el derecho a la información será garantizado por el Estado". 
(Serdán, 2017; Cesar y Fernández, 2017) ${ }^{11}$. Este trabajo extremadamente útil, realizado por ciudadanos voluntarios, mostró la capacidad informativa de la sociedad civil (siendo las redes sociales acusadas por el gobierno y los medios masivos de comunicación de propagar rumores), poniendo en jaque al gobierno como fuente de noticias.

\section{El rumor de Frida Sofía}

Aunque se inscribe en la lista de rumores que surgieron después del sismo (cf. cuadro 1), decidimos dar un tratamiento diferente al rumor de Frida Sofía por tres razones: (1) lo produjo una fuente gubernamental con la complicidad de una televisora; (2) esta noticia falsa tuvo un impacto considerable en la opinión pública nacional e internacional; y (3) la misma fuente que lo originó reconoció que se trataba de un rumor. Estas tres características hacen del rumor de Frida Sofía un caso ejemplar, muy bien documentado, que nos permitirá comprender el complejo juego de expectativas e intereses en una situación de emergencia.

En un momento en el cual los equipos de rescate, junto con decenas de miles de voluntarios, trabajaban día y noche para encontrar sobrevivientes debajo de los escombros en varios puntos de la capital, la atención de los medios se centró en una escuela que se había derrumbado en la delegación Tlalpan, al sur de la Ciudad de México. Se contabilizaron 209 instituciones escolares dañadas por el temblor del 19 de septiembre en la capital del país, pero la escuela privada Enrique Rébsamen era la única que se había desplomado sobre escolares. Al caos que reinaba en las primeras horas después del derrumbe, siguió un control del

\footnotetext{
11 Cabe agregar que el mismo presidente de la República, en una ceremonia de reconocimiento a la labor de los rescatistas celebrada el 13 de octubre del 2017, mencionó: "Vimos la tarea de jóvenes que, a través de las redes sociales, o de personas que, a través de las redes sociales, estuvieron dando información de dónde había daños, dónde había personas atrapadas, dónde había que prestar labores de auxilio y de apoyo".
} 
perímetro y de las actividades de rescate por la Armada de México. Los uniformados se hicieron cargo de organizar las labores, dejando a los demás socorristas profesionales y voluntarios en un segundo plano. En ese plantel, donde estaban escolarizados 400 menores en kínder, primaria y secundaria, se presentaron numerosos medios de comunicación nacionales e internacionales, que hicieron guardia desde la tarde del día 19 (Iñigo Arredondo, 2017; Vela, 2017a; Núñez, 2017). Esperaban documentar en vivo el rescate de la niña Frida Sofía, cuya existencia había sido dada a conocer por el almirante Vergara Ibarra, quien afirmó: "Hay una niña que aún escuchamos con vida. Y es ahí donde realizamos el mayor esfuerzo porque está muy complicado el rescate" (Villamil, 2017). Televisa transmitía todos los detalles sobre el caso. Al día siguiente, el presidente de la República, acompañado por los secretarios de Gobernación y de Educación, y de Marina, se presentó en el sitio del derrumbe. Mientras, los periodistas Denise Maerker y Joaquín López Doriga, de Televisa, se habían apropiado de la cobertura mediática del rescate. En entrevista, el secretario de Educación señaló:

Todos los esfuerzos están en poder encontrar a esta niña y llegar a ella y, eventualmente, a más niños... He tenido contacto con los padres de familia, con los maestros; pero no hemos tenido contacto con el mando de la Marina, ni del Ejército; tampoco con familiares de quien pudiera ser esta niña (a quien) se ha identificado como Frida Sofía. No hemos podido contactar a los papás, ni algún familiar. (Cruz Salinas, 2017)

Aunque la ausencia de contacto con familiares era muy llamativa, extraña incluso, Televisa siguió sobredimensionando las labores de rescate en la escuela Enrique Rébsamen, con la organización de un "show" mediático, llegando al extremo de transmitir en vivo 16 horas seguidas, logrando una tasa de audiencia excepcionalmente elevada (Villamil, 2017). El nombre de Frida Sofía se volvió trending topic en Twitter. La periodista de Televisa 
que se quedó 25 horas en el Colegio Rébsamen afirmó que había hablado con los familiares, pero que éstos pedían el anonimato, que no querían ser entrevistados en televisión y también habían solicitado que no se divulgara el apellido de su hija. Por otro lado, un socorrista voluntario afirmó al semanario Proceso haber escuchado a Frida Sofía el jueves 21 (Villamil, 2017), otro socorrista publicó un video en Youtube, diciendo que sí se habían comunicado con una niña llamada Sofía, pero que la Marina los sacó después de que se perdió toda comunicación a raíz de una mala maniobra ${ }^{12}$. Otro rescatista subió un video en el que afirmaba que se habían comunicado con una niña llamada Sofi, que su equipo y él estaban trabajando para alcanzarla, pero que los oficiales de la Marina los sacaron a todos para poder "colgarse la medallita" y obtener un ascenso ${ }^{13}$. La confusión informativa cundió.

TV Azteca, citando a la Secretaría de Educación Pública, reportó que en la lista de niños del Colegio no había ninguna menor de nombre Frida Sofía. Empezó a surgir dudas sobre la versión de la Secretaría de Marina (Semar)-Televisa, pero el rumor terminó por desbaratarse por completo cuando la conocida periodista Carmen Arristegui entrevistó a un joven traductor para los rescatistas alemanes, quien contó que un oficial de la Policía Federal le había confiado que esa niña no existía y que todo era un montaje. Inmediatamente, en las redes sociales circuló un gran número de mensajes de indignación y enojo en contra de la televisora y de las autoridades. A mediodía, el subsecretario de la Marina, Ángel Enrique Sarmiento, se vio obligado a aclarar escuetamente que el caso de la niña Frida Sofía "no fue una realidad", que no habían tenido conocimiento del nombre de esa niña y que habían cotejado con la lista proporcionada por la Secretaría de Educación Pública que no había ya más menores debajo de los escombros (Moreno, 2017; Vela, 2017b). Los dos locutores estrellas de Televisa antes mencionados expresaron su sorpresa e indignación y

\footnotetext{
Recuperado de https://www.youtube.com/watch?v=Hu1itrd01qs

Recuperado de https://www.youtube.com/watch?v=9sAIgRmRD4Q
} 
responsabilizaron a la Semar de ese "error informativo", y aseveraron haber siempre trabajado para contrarrestar rumores. "El oficial mayor de la Marina José Luis Vergara, la 'fuente oficial' de Televisa, también se dijo sorprendido por las declaraciones del subsecretario y aseguró que si la información proporcionada fue errónea no fue por un afán malévolo" (Villamil, 2017). Mientras tanto, las autoridades prohibieron a los familiares de las víctimas de la escuela hablar públicamente para revelar que no había menores con vida debajo de los escombros.

Al mismo tiempo, un nuevo rumor empezó a circular por WhatsApp: era un mensaje de voz de una mujer que decía que se encontraba afuera del Colegio Rébsamen con muy poca pila en su celular, que los rescatistas le habían dicho que iban a meter un bulldozer, que el gobierno estaba manipulando la información con Televisa y que rescatistas americanos le habían dicho que había todavía cinco niños vivos. Apareciendo en un momento de mucha zozobra, este rumor, que mezclaba informaciones conocidas con una revelación dramática, se difundió con gran velocidad en las redes sociales. A las 22 horas de ese día, 21 de septiembre, los dos oficiales de la Armada dieron una conferencia de prensa en la cual aseveraron que nunca quisieron generar falsas expectativas, que se basaban en análisis técnicos y testimonios de rescatistas para compartir la información en tiempo real, y que no sabían si era niña o adulta. Este desmentido del desmentido previo, elíptico y barroco, responsabilizaba indirectamente a otros (rescatistas y analistas) de lo sucedido. Esta declaración de apenas 2:20 minutos de duración provocó una ola de consternación y enojo en la opinión pública, que se sentía engañada —reacción alimentada también por Televisa ${ }^{14}$. Tan fuerte era el malestar

$14 \quad$ Al haber encontrado inmediatamente un chivo expiatorio en los dos más altos oficiales de la Marina después del secretario, Televisa no se vio en la necesidad de ofrecer una disculpa a sus millones de televidentes que había engañado durante varios días, ni tampoco de disculparse por no haber cotejado la información, ni de lamentar lo sucedido (lucrar con la tragedia para obtener una audiencia inaudita). La televisora se lavaba de toda culpa transfiriendo gratuitamente a los uniformados 
de los televidentes que \#ApagaTelevisa se volvió tendencia al día siguiente en las redes sociales.

Al final del trabajo de rescate, se había salvado a 11 menores y retirado de la escuela derrumbada los cuerpos de 19 menores y 6 adultos fallecidos ${ }^{15}$.

Cabe reflexionar ahora sobre la aparición del nombre Frida Sofía para designar a una niña que nunca existió. Varias son las pistas para remontar al origen de dicho nombramiento. El nombre de Frida es conocido por referirse a la célebre pintora Frida Khalo, compañera de Diego Rivera, pero en la situación de emergencia de septiembre del 2017 Frida estuvo en boca de todos por ser el nombre de la perrita rescatista que se volvió una celebridad en las redes sociales, inmortalizada con sus botines azules y sus lentes de protección. Aunado a lo antes señalado, en el sitio del derrumbe, unos rescatistas mencionaron haberse comunicado con Sofía, otros con Sofi, mientras que la locutora de Televisa repitió incansablemente el de Frida Sofía, el cual fue retomado masivamente por los medios de comunicación y aceptado como tal por el público. Hay que anotar que en sus dos desmentidos (primero desmintió la existencia de "dicha niña", y unas horas más tarde desmintió en dúo el primer desmentido afirmando que tal vez la niña había sido confundida con una mujer que posiblemente podría estar con vida debajo de los escombros), el número 2 de la Marina no mencionó nunca a Frida Sofía, sino que se refirió a ella como "de una niña" y "dicha niña". Asimismo, no existe certeza sobre la fuente original que bautizó Frida Sofía a una niña inexistente.

Pero la historia se repite. El 19 de septiembre de 1985, temprano en la mañana, un terremoto de magnitud 8.2 en la escala

\footnotetext{
la entera responsabilidad de lo sucedido. De manera general, el chivo expiatorio es la expresión de una ruptura en el orden social, el fin de las diferencias que definen los órdenes culturales (Girard, 1986, p. 23).

15 Cabe señalar que, dentro de los niños fallecidos, estaba el hijo de siete años del periodista Oscar Raúl Vargas, a quien se le rindió un sonado homenaje por pertenecer al equipo de fútbol del América, en la categoría infantil.
} 
de Richter devastó la capital de México. La amplitud del desastre (oficialmente se reconocieron 10.000 muertos, pero se estima que el número de víctimas podría alcanzar el doble), la débil eficacia de los servicios de emergencia y de los cuerpos de seguridad, las expectativas para encontrar sobrevivientes aunados al control de la información por el partido hegemónico, constituyeron un terreno fértil para los rumores. El rumor más destacado fue el de un niño de 9 años, Luis Ramón, apodado "Monchito", quien supuestamente se encontraba con vida debajo de los escombros al lado de su abuelo (Comas, 1985). Las similitudes de los rumores de Monchito en 1985 y Frida Sofía en 2017 son sorprendentes. Después del dictamen negativo de diferentes brigadas de socorristas internacionales y nacionales, un grupo de jóvenes rescatistas dijo haberse comunicado con Monchito, de la misma forma que brigadistas voluntarios en la escuela Enrique Rébsamen aseveraron haberse comunicado milagrosamente con Frida Sofía: "Si no puedes hablar das dos golpes", "Si eres un adulto: da un golpe; si eres un niño: da dos golpes", fueron las mismas palabras empleadas para comunicarse con el niño y con la niña. En ambos casos, la búsqueda de menores recibió toda la atención de los medios de comunicación y sobre todo de Televisa, cadena televisiva que se hizo dos veces portavoz de un rumor casi idéntico ${ }^{16}$.

En el sitio del derrumbe se presentaron en 2017 el ex arzobispo de México, varios secretarios de Estado y el mismo presidente de la República, mientras que en 1985 desfilaron dos hijos del presidente, el embajador de Estados Unidos, personalidades del mundo del espectáculo, mientras que el presidente Miguel de la Madrid dio órdenes para que se siguiera buscando a Monchito. Pero el rumor terminó cuando rescatistas y reporteros informaron que Monchito nunca estuvo con vida (algunos reporteros afirmando incluso que nunca existió), y en el caso de Frida Sofía la falsa información se descubrió cuando un subsecretario de la Marina dio a conocer que

16 Cabe agregar que Televisa había participado anteriormente en la propagación del rumor de los Pitufos en 1983 (Zires, 2011, pp. 302-303). 
nunca existió una alumna con ese nombre en dicha escuela. Luego, al escuchar el anuncio de que se iba a emplear máquina pesada para remover los escombros en el número 185 de la calle Venustiano Carranza de la Merced, en 1985, como en Coapa en 2017, hubo una reacción inmediata de la opinión pública para exigir seguir buscando sobrevivientes. En ambos casos, los desmentidos no hicieron perder la esperanza de encontrar personas vivas, y voluntarios continuaron con su labor de rescate a pesar del desmentido.

Esta reaparición de un rumor con las mismas características a más de tres décadas de distancia puede explicarse por el hecho de que se centra en un niño y una niña cuya vida está en peligro. La vulnerabilidad de los menores en una sociedad de riesgo ${ }^{17}$ permite comprender por qué un régimen de verosimilitud como el rumor se centre en los niños. Esta particular "sensibilidad del cuerpo social" (Kapferer, 1987, p. 135) se manifiesta en el número significativo alto de rumores que circulan poniendo en escena a menores de edad ${ }^{18}$. En el caso que nos ocupa, el contexto general es el de una situación de emergencia posterior a un terremoto excepcionalmente grave, que provocó numerosas pérdidas humanas. Detrás del rumor de Monchito y del rumor de Frida Sofía está la idea subyacente de salvar una vida, la vida de un ser vulnerable. Asimismo, el rescate mediático de un(a) niño(a) pretende ser una prueba de lo que el Estado es capaz de hacer: resucitar a alguien de entre las víctimas de un desastre natural. Es ofrecerle una segunda oportunidad, la de vivir su vida. Es ir en contra de la fatalidad y de la resignación, obsequiando a la sociedad una nota de esperanza. La luz dentro de la oscuridad. La vida en medio de la muerte. Un terremoto mortífero de gran amplitud que se repite (el mismo día) llama la sociedad a interrogarse sobre su vulnerabilidad y la fragilidad de sus instituciones. "El eterno regreso del rumor, es-

\footnotetext{
17 México puede ser considerado como una sociedad de riesgo, debido a las estadísticas judiciales y también a las encuestas sobre la percepción del riesgo por parte de la población.

18 Las versiones del rumor de los Pitufos (Zires, 1991, 2001).
} 
cribe Kapferer (1987, p. 136), sería el testigo de la actualización, a partir de acontecimientos propicios, de un sistema explicativo profundamente arraigado en la conciencia colectiva". Una tragedia que involucra niños tiene una mayor proyección social porque moviliza sentimientos afectivos profundamente arraigados en el ser humano.

\section{Conclusiones}

Los rumores tienen una predilección por las situaciones de crisis, ya sean guerras, conflictos políticos y sociales, así como situaciones de emergencia por desastres naturales. En esas circunstancias, las informaciones verosímiles pretenden decir lo que los medios de comunicación ocultan, aseveran complementar noticias oficiales y, en algunos casos, hacen anuncios predictivos de catástrofes inminentes. Pero se inscriben todas, durante su corta existencia, dentro de un régimen de verosimilitud. El rumor se alimenta de la vulnerabilidad de un sector de la población o de la sociedad en su totalidad, para darse a conocer de boca en boca, en los medios de comunicación y en las redes sociales. Al circular, va creando lo que podríamos llamar una "comunidad de creyentes" (ecclesia, en latín), cuya extensión puede abarcar en su punto más culminante a una parte de comunidad internacional. Debe notarse que la gente cree en una información que le parece plausible, por lo que no considera a ésta como un rumor, ya que el término "rumor" convoca la idea de falsedad, engaño y credulidad. Una vez desmentido, gran parte de quienes difundieron el rumor no se acuerdan de él: fue una noticia fugaz que nadie vio, ni creyó (Fernández Poncella, 2014). Un rumor nace, se expande y muere para, en algunos casos, resucitar tiempo después en el mismo u otros lugares ${ }^{19}$. Sigue siendo desde tiempos remotos una forma de comunicación en las sociedades de riesgo.

19 El rumor puede brincar fronteras y resurgir periódicamente en el transcurso de varias décadas. Es por ejemplo el caso del rumor de los tatuajes con personajes de 
En México, el rumor es considerado por las autoridades como un problema. Es para ellas una práctica comunicativa que representa un riesgo para la paz social, porque es difusa, acéfala y amenaza la estabilidad de las instituciones. A nivel federal, dependencias como la Secretaría de Gobernación y sobre todo el Cenapred han solicitado reiteradamente a la población, mediante boletines, comunicados, carteles y entrevistas, no difundir rumores en caso de desastre natural. Llamamos a estos mensajes "antirumores", porque no se dirigen en contra de un rumor específico, sino en contra de un modo genérico de comunicar e informar que es el rumor ${ }^{20}$. Estos mensajes oficiales tenían un triple propósito de: 1) recordar que los ciudadanos deben informarse exclusivamente con las fuentes oficiales, 2) los ciudadanos deben averiguar la autenticidad de una información antes de difundirla, 3) en caso de emergencia, lo único que se debe hacer es marcar al 911. Después del terremoto del 19 de septiembre del 2017, los medios masivos de comunicación hicieron suyos estos llamados a la pasividad en nombre de una eficiencia omnímoda del Estado. Asimismo, repitieron incansablemente a los televidentes y radioescuchas: “Quédense en sus casas. No salgan. Dejen las vialidades libres para los servicios de emergencia. Nosotros les informaremos". Radios y televisoras insistían también en la no difusión de rumores porque entorpecían las labores de rescate y la acción del gobierno. Llama mucho la atención de que los grandes consorcios del sector de la comunicación en México (Grupo Televisa, Grupo Fórmula, Grupo Acir, Grupo Imagen...) aceptaron todos, de manera dócil, transmitir repetidamente los discursos oficiales que fomentaban la apatía y la disciplina entre la población. Esta oportuna convergencia de interés del sector

Disney que contenían LSD, que se originó en los Estados Unidos, luego apareció en Canadá y tiempo después surgió en el sur de Francia (Reumaux, 2009).

20 Por su parte, Morin (1982, pp. 67-78) designaba por "antimitos" dos conductas: 1) el antimito espontáneo, es decir, la incredulidad; 2) el antimito de disuasión, que conlleva intervenciones públicas del gobierno y diferentes actores, así como una intervención judicial. 
privado con el gobierno reforzó ciertamente el papel crítico, libre e independiente de las redes sociales en este periodo de crisis. De hecho, un excelente tema de investigación sería el análisis del papel de los medios masivos de comunicación en la semana que siguió al sismo del 19 de septiembre.

Aun así, numerosos fueron los rumores que circularon a raíz del terremoto que azotó a la Ciudad de México y Estados colindantes ese 19 de septiembre. Apenas unas horas después de este terrible acontecimiento, se propagó información explicando que el sismo había sido provocado por explosiones atómicas realizadas en Corea del Norte, rumores sobre la inminencia de un sismo de gran magnitud, edificios que se habrían caído, etc. Además, en cada sitio de derrumbe circulaban pequeños rumores, $\mathrm{y}$ en las redes sociales se difundían noticias verosímiles al lado de informaciones auténticas. La situación de emergencia propició una azarosa búsqueda de información al margen de las noticias divulgadas por los medios masivos de comunicación: la gente quería saber con exactitud lo que estaba pasando. En el presente estudio hemos visto que cada uno de estos rumores respondía a una carencia de información, a la desconfianza de la ciudadanía en las autoridades y, paradójicamente, a la necesidad de tener certezas sobre asuntos de importancia. Para cada información falsa existía elementos certeros que le permitía entrar, hasta cierto grado, en un régimen de verosimilitud.

La gran mayoría de rumores que circularon en los días posteriores al 19 de septiembre fueron desmentidos por las autoridades y los organismos competentes. La Presidencia de la República y la Secretaría de Gobernación fueron las principales unidades administrativas que se encargaron de denegar la veracidad de esas noticias, lo cual muestra la importancia que el Poder Ejecutivo Federal dio al control de la información en las redes sociales. Algunos desmentidos fueron expresados en entrevista por el mismo presidente de la República y retomados inmediatamente por las dos instancias antes mencionadas como comunicados oficiales. Por su parte, el Cenapred se encargó de desmentir en 
varias ocasiones la posibilidad de predecir un terremoto y su intensidad. Es interesante notar que los desmentidos eran afirmaciones positivas: "los trabajos de rescate no se suspenden", "los trámites para obtener apoyos se hacen de esa forma", etc., cuando emanaban de la Presidencia de la República, mientras que los desmentidos adoptaban la forma de afirmaciones negativas: "tal información es falsa porque no puede suceder tal fenómeno", cuando eran otras dependencias de gobierno, la Universidad Nacional Autónoma de México (UNAM) o la Organización de las Naciones Unidas (ONU) que reaccionaban frente a un rumor que mencionaba su nombre o un asunto de su competencia.

Estos dos tipos de desmentidos tienen objetivos distintos: el primero informa, precisa y tranquiliza sin referirse explícitamente al rumor. Es la voz de autoridad que manda y que da una información oportuna a la ciudadanía. El segundo tipo de desmentido descalifica el contenido informativo del rumor y a quienes creen en él, dejando entender que los que difunden esta información falsa son personas crédulas e ignorantes. En todo caso, es difícil evaluar el impacto que los repetidos desmentidos tuvieron sobre las noticias falsas; sin embargo, lo que sí podemos afirmar es que los rumores fueron tratados por las autoridades como ataques en su contra, en un escenario asemejado a una guerra informativa.

El caso del rumor de Frida Sofía es emblemático porque fue muy ampliamente difundido por los medios masivos de comunicación, al grado que pasó a ser una noticia a nivel internacional. El derrumbe del Colegio Enrique Rébsamen sobre escolares y la posibilidad de encontrar a uno de ellos, atrapó la atención del público en virtud de una particular "sensibilidad" del cuerpo social respecto de menores cuya vida está potencialmente en peligro. El rescate hipermediatizado de la niña Frida Sofía permitió a Televisa conseguir una audiencia pocas veces alcanzada, al tiempo que enaltecía las labores de los elementos de la Marina. Este doble protagonismo terminó abruptamente cuando se confirmó que nunca había existido una niña atrapada debajo de los escombros. El doble desmentido de los altos mandos de la Marina, en 
pos de esclarecer esta confusión informativa, contribuyó aún más al descrédito del gobierno y de Televisa. Más profundamente, el rumor de Frida Sofía exhibió a una institución gubernamental difundir con provecho una noticia falsa, cuando el mismo gobierno federal llevaba una campaña informativa "antirumores" que señalaba reiteradamente a los ciudadanos por difundir rumores en las redes sociales. Esta aporía provocó un sentimiento de consternación y enojo por parte de todos quienes creyeron en esta noticia falsa, y por ende reforzó aún más el descrédito de la ciudadanía hacia los organismos oficiales. El rumor de Frida Sofía —que repitió el rumor del niño Monchito, igualmente difundido por Televisa en el sismo de 1985- marca una etapa en la divulgación de rumores por parte de las autoridades. La propagación de informaciones falsas por las autoridades es una estrategia de propaganda muy empleada pero poco documentada ${ }^{21}$. Ciertamente, el desarrollo de futuras investigaciones sobre este tema permitirá comprender mejor el uso institucional de rumores en los países latinoamericanos.

\section{Referencias}

Aldrin, P. (2003). Penser la rumeur. Une question discutée des sciences sociales. Genèses, 50, 126-141.

Allport, G. y Postman L. (1987). Psicología del rumor. Buenos Aires: Psique.

Bauman, Z. (2007). Miedo líquido. La sociedad contemporánea y sus temores. Barcelona: Paidós.

Brodu, J. L. (1990). Une rumeur de sécheresse. Communications, 52, 85-97.

Cenapred. (2017). Ante el rumor de un sismo ¡infórmate! 30 de mayo. Recuperado de https://www.gob.mx/cenapred/articulos/ante-el-rumor-de-un-sismo-informate?idiom=es

${ }^{21}$ Puede mencionarse el estudio de Lutz y Padilla (2012) sobre el rumor del nopal chino, en el cual mostraron que esta noticia falsa había sido originada por la Subsecretaria de Desarrollo Agropecuario de la Delegación de Milpa Alta del sur de la Ciudad de México. 
Chomsky, N. (2002). La propaganda y la opinión pública. Conversaciones con David Barsamian. Barcelona: Crítica.

Comas, J. (1985). Monchito, el rescate imposible. El país, 7 de octubre. Recuperado de https://elpais.com/diario/1985/10/07/ internacional/497487617_850215.html

Clavandier, G. (2007). Recourir au fait divers dans les situations postcatastrophiques: le cas des rumeurs. Les Cahiers du journalisme, 17, 90-105.

Cruz Salinas, J.C. (2017). Frida Sofía y la 'zona cero' del caos. Proceso, núm. 2134, 24 de septiembre, pp. 17-18.

DiFonzo, N. y Bordia P. (2007). Rumor, Gossip and Urban Legends. Diogenes, 213, 19-35.

El Heraldo de México. (2017). ¿Cómo ayudar a compartir la información? 21 de septiembre. Recuperado de https://heraldodemexico.com.mx/pais/segob-actualiza-a-273-cifra-demuertes-tras-sismo/

Fernández Poncela, A. M. (2014). Epidemia de rumores: expresión de miedos, riesgos y desconfianza. Convergencia, 21(65), 193217.

Froissart, P. (2000). L'invention du "plus vieux média du monde. MEI Médiation et Information, 12-13, 183-195.

Girard, R. (1986). El chivo expiatorio. Barcelona: Anagrama.

Iñigo Arredondo, D. (2017). Frida, ya vamos, no te desesperes. El Universal, núm. 36474, 21 de septiembre, p. A6.

Kapferer, J. N. (1987). Rumeurs. Le plus vieux média du monde. París: Seuil.

Kapferer, J. N. (1990). Le contrôle des rumeurs. Communications, 52, 99118.

Loaeza, G. (1977). La política del rumor. México, noviembre diciembre de 1976. Foro Internacional, Vol. XVII, 4(68), 557-587.

Lutz, B. y Padilla A. (2012). El rumor del nopal chino en México: construcción institucional y efectos sociales de informaciones falsas. Comunicación y Sociedad, 17, 179-204.

Lucas, N. (2017). Las noticias falsas que cuentan otro terremoto del 19 de septiembre. El Economista, 23 de septiembre. Recuperado de https://www.eleconomista.com.mx/politica/Lasnoticias-falsas-que-cuentan-otro-terremoto-del-19-de-septiembre-20170923-0004.html 
Miaille, M. (1999). La rumeur entre société civile et Etat. En F. Reumaux (Coord.), Les oies du Capitole ou les raisons de la rumeur (pp. 75-89). París: CNRS.

Moreno, T. (2017). Frida Sofía no fue real; la Marina se disculpa. El Universal, núm. 36475, 22 de septiembre, p. A6.

Morin, E. (1982). La rumeur d'Orléans. París: Seuil.

Núñez, E. (2017). Persiste esperanza. Reforma, Sección Ciudad, núm. 8667, 21 de septiembre, p. 1.

Oh, O., Hazel, K. \& Rao R. (2010). An Exploration of Social Media in Extreme Events: Rumor Theory and Twitter During the Haiti Earthquake 2010. Thirty First International Conference on Information Systems, St Louis. Recuperado de http:/ /aisel. aisnet.org/icis2010_submissions/231/

Paillard, B. (2009). La rumeur ou la preuve ordinaire. Communications, $84,119-135$.

Presidencia de la República. (2017a). Mensaje del presidente Enrique Peña Nieto. Recuperado de https://www.gob.mx/presidencia/es/prensa / mensaje-del-presidente-enrique-penanieto-127544?idiom $=\mathrm{es}$

Presidencia de la República. (2017b). Las labores de rescate de las personas en la Ciudad de México continúan: no se suspenden. Recuperado de https://www.gob.mx/presidencia/es/ prensa/las-labores-de-rescate-de-personas-en-la-ciudadde-mexico-continuan-no-se-suspenden-enrique-penanieto?idiom $=\mathrm{es}$

Procuraduría General de la República. (2017). ¿Cómo ayudar a las personas afectadas por el \#sismo? Recuperado de https: / / www.gob.mx/pgr/articulos / como-ayudarayudaaayudar?idiom $=\mathrm{es}$

Renard, J. B. (2006). Rumores e violência. Revista FAMECOS, 29, 20-28.

Reumaux, F. (1990). Traits invariants de la rumeur. Communications, 52, 141-159.

Reumaux, F. (2009). Acerca de la definición del rumor y sus significados. Versión, 23, 103-130.

Roa, W. (2017). A tres meses, aquí las cifras del sismo del 19 de septiembre. Excelsior. 19 de septiembre.

Rouquette, M. L. (1990). Le syndrome de la peur. Communications, 52, 119-123. 
Rouquette, M. L. (2009a). Representaciones e ideología: una explicación psicosocial. Polis, 5, 143-160.

Rouquette, M. L. (2009b). Los rumores y la cuestión de la verdad. Versión, 23, 157-166.

Secretaría de Gobernación. (2017a). Información relacionada con el acceso a recursos del Fondo de Desastres Naturales, FONDEN. Boletín No 320/17, del 22 de septiembre. Recuperado de https://www.gob.mx/segob/prensa/informacion-relacionada-con-el-acceso-a-recursos-del-fondo-de-desastres-naturales-fonden?idiom $=\mathrm{es}$

Secretaría de Gobernación. (2017b). Corte informativo con datos preliminares del sismo. Recuperado de https:/ /www.gob.mx/ segob/prensa / corte-informativo-con-datos-preliminarestras-sismo?idiom $=\mathrm{es}$

Serdán, A. (2017). Lo que vi en \#Verificado19s. Animal político, 27 de septiembre. Recuperado de http://www.animalpolitico. com/blogueros-el-dato-checado/2017/09/27/lo-vi-verificado19s/; Cesar, A. y A. Fernández. (2017). \#Verificado19s puso orden a la ayuda tras el sismo. El Financiero, núm. 9938, 24 de septiembre, p. 7.

Turati, M. (2017). Rebeldía salvadora. Proceso, núm. 2134, 24 de septiembre, p. 16.

Vanguardia. (2017). Carmen Salinas culpa a Corea del Norte del sismo en México. Recuperado de http://www.vanguardia.com. $\mathrm{mx} /$ articulo/carmen-salinas-culpa-corea-del-norte-delsismo-en-mexico

Vela, D.S. (2017a). Marina, Sedena y Topos, a punto del milagro de rescatar a Frida. El Financiero, núm. 9935, 21 de septiembre, p. 4.

Vela, D. S. (2017b). La Marina se disculpa por la versión falsa del caso Frida Sofía. El Financiero, núm. 9936, 22 de septiembre, p. 7.

Villamil, J. (2017). Bajezas mediáticas. Proceso, núm. 2134, 24 de septiembre, p. 20.

Villamil, J. (2017). La pelea por el rating y la invención de Frida Sofía. Proceso, 3 de octubre.

Young, K. (2001). La opinión pública y la propaganda. México D.F.: Paidós.

Zires Roldán, M. (1991). El rumor de los Pitufos. Un acceso a las culturas orales en México. Estudios sobre las culturas contemporáneas, IV(12), 83-99. 
Zires Roldán, M. (2001). Del rumor al tejido cultural y saber político. México D.F.: UAM-X.

Zires Roldán, M. (2017). Rumores en redes sociales en contextos de violencia: Veracruz, agosto de 2011. Razón y Palabra, 21(96), 723-760. Recuperado de http://www.redalyc.org/ pdf/1995/199551160038.pdf 